\title{
Academic Research Council Coronary Stent Thrombosis Timing
}

National Cancer Institute

\section{Source}

National Cancer Institute. Academic Research Council Coronary Stent Thrombosis

Timing. NCI Thesaurus. Code C123424.

Categorization of the timing of coronary stent thrombosis occurrence per the classification schema described by the Academic Research Consortium (ARC). 